\title{
Typological guidance in the acquisition of V2 Dutch ${ }^{1}$ Jacqueline van Kampen
}

\begin{abstract}
The main issue of the paper will be the identification of the clause-initial finite verbs as $\mathrm{C}^{0}$ in Celtic as well as in Germanic. Framing $\mathrm{C}^{\mathrm{o}}$ as the core point of V1 and V2 types of languages will here be justified by an acquisitional analysis of $\mathrm{V}<+$ fin $>$-to- $\mathrm{C}^{0}$ in Dutch. The background of this argument will be Jakobson's (1942) thesis that there is a hierarchy of typological features and that this hierarchy will show up in language acquisition. Some properties of grammar are of course acquired before others, but, more interestingly, the major typological properties of grammar are invariably the first to be acquired. They happen to serve as the acquisitional basis for the more language-specific properties of grammar. Typological properties survive so well in the history of grammar, because they are the system's bootstrap for learnability.

The successive acquisition steps indicate how grammar is built up by input-control in a flexible way. In a first step, Celtic V1 and Germanic V2 share the basic property of a clause-typing head $\mathrm{V}<+$ fin $>$ in $\mathrm{C}^{\mathrm{o}}$. The acquisition data suggest that finiteness, not tense, must be the trigger for verb movement. The subject obligation, as well as tense and agreement markings come in after verb movement. The subject obligation seems to get underlined, rather than to be derived from uninterpretable phi-features. The last section discusses the growing importance of Spec.C in Dutch and the typological difference this will cause between V1 and V2 languages.
\end{abstract}

Keywords acquisition, typological hierarchy, Germanic, Celtic, verb movement, subject obligation

\section{Background and set-up of the paper}

A more precise attention to the order of acquisition steps reveals an acquisition hierarchy of typological properties. Typological properties turn out to be a kind of bootstraps for decoding and mastering the grammatical system. I will use a longitudinal analysis to argue that there is a fundamental parallel between V1 Celtic and V2 Germanic, although by the same logic they soon show fundamental differences as well.

\subsection{Typological features and Jakobson's perspective}

Celtic V1 and Germanic V2 have the finite verb in a clause-initial position. They may also have an element in the position just before the finite verb. The typological question is whether the positions of the finite verb and the preverbal element can be identified as $\mathrm{C}^{\mathrm{o}}$ and Spec.C. If so, the fairly rare V2 type of language and the more common V1 type of language appear as variants. The V2 language type would only be less restricted in its options for constituents in the Spec.C. Below, I will support the thesis that Celtic V1 and Germanic V2 share a basic typological property of $\mathrm{V}<+$ fin $>$-to- $\mathrm{C}^{0}$ movement, while they

\footnotetext{
1 The research for this paper was supported by NWO (grant 360-70-290) and the UiL OTS (Utrecht University).
} 
differ substantially in the functions for the preverbal element. The arguments come from first language acquisition.

Longitudinal data from first language acquisition support the view that the clauseinitial finite verb is acquired as a kind of clause-typing operator that is best identified as $\mathrm{C}^{\mathrm{o}}$. The difference between Celtic V1 and Germanic V2 comes in a later acquisition stage, when Germanic develops the Spec.C for full phrases, whereas Celtic develops different constructions for a preverbal element. The question is which property of the language favours this typological difference. I will suggest that the curious "antiagreement" in V1 languages may be a factor. It prevents that pronominal unstressed subjects appear in a Spec.C. By contrast, non-pro-drop Germanic starts its full use of a Spec.C with just such pronominal subjects.

The main issue of the paper will be the identification of the clause-initial finite verbs as $\mathrm{C}^{\mathrm{o}}$ in Celtic as well as in Germanic. Framing $\mathrm{C}^{\mathrm{o}}$ as the core point of V1 and V2 type of languages will be justified by a detailed acquisitional analysis of V2 Dutch. Before entering that issue (V2 in Dutch child language), I would like to underline the general point, already advanced in Jakobson (1942), that language acquisition is relevant for discussing the hierarchy of typological features. Some properties of grammar are acquired before others and, more interestingly, the major typological properties of grammar are invariably the first to be acquired. They serve as the acquisitional basis for the more language-specific properties of grammar. Typological properties survive so well in the history of grammar, because they are the system's bootstrap for learnability. I pursue here the ideas in (1), already applied in Van Kampen (1997).

a. The form of early child language represents a predictable and systematic reduction of the input. The child's input filter is based on the child's ignorance. All grammatical features (functional categories) are left out as unidentifiable.

b. Minimal differences between the reduced grammar and the adult input enter into a linear order of cues determined by input frequencies.

c. Language types are determined in maximally simplified structures. Typological features are those that pass the child's early input filter as first.

A bit more elaborated, this could be formulated as follows. The differences between the The input reduction gives rise to minimal, i.e. binary, structures, for example as in (2).

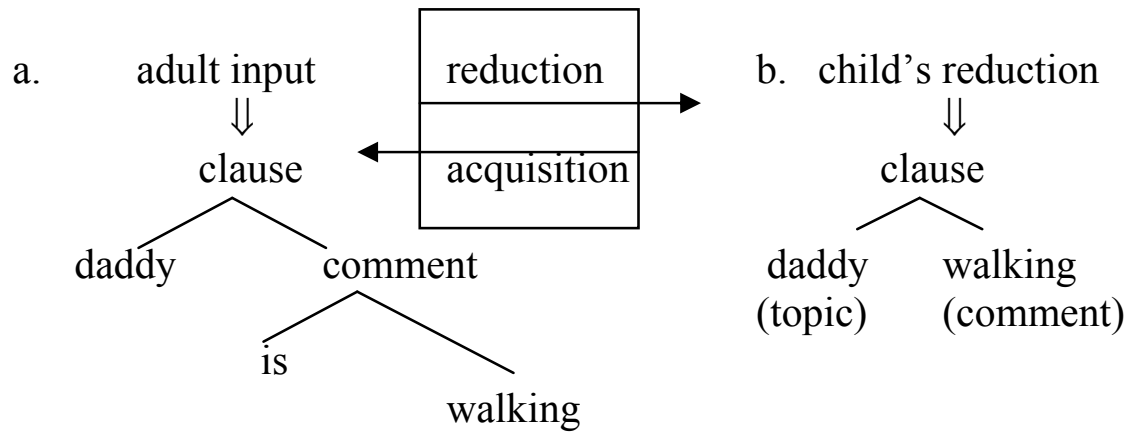


The grammatical category that is to be added in (2)b, characterizes a class of comments (the -ing class). Adding the copula as a fixed property of certain comments turns the haphazard notion of predicate cue into a predictable input treelet. The notion of cue (Dresher 1999), and the more advanced notion of treelet (Fodor 1998) are necessary, but ambiguous. They may suggest that the acquisition procedure is guided by sets of grammatical a prioris. That, just that, is rejected by the present approach. Cues/treelets are derived from the input by a "mechanical" reduction procedure. This language acquisition device harbours no specific grammatical information. My basic contention is that there are no grammatical a prioris as such. Each (typological) parameter is due to a treelet of its own derived from input reduction (Evers \& Van Kampen 2001, 2008, Van Kampen 2004a).

There are several favourable circumstances for this statement. In the first place, it may now fly with the green card of "strong minimalist thesis"(Chomsky 2005). In the second place, Jakobson (1942) already predicted that the order of acquisition steps would reveal a typological hierarchy. Moreover, a stepwise order of acquisition steps is not a theoretical speculation. It can be measured by constructing longitudinal graphs from files in the CHILDES database (MacWhinney 2006). If focused on the right data, they picture the growing percentages of the successful production for each grammatical feature. Language acquisition turns into a series of ever more specified grammars $G_{i}$ that approaches the target grammar $\mathrm{G}_{\mathrm{n}}$. Each acquisition step identifies the elementary context property $P_{i}$ of a grammatical category. The diagram in (3), adapted from (Chomsky 1975: $119)$, may be used.

$$
\stackrel{\mathrm{P}_{\mathrm{i}}}{\mathrm{G}} \underset{\mathrm{G}}{\mathrm{G}---} \quad \mathrm{G}_{\mathrm{i}-1} \Rightarrow \mathrm{G}_{\mathrm{i}} \quad---\mathrm{G}_{\mathrm{n}}
$$

Each acquisition step $G_{i-1} \Rightarrow G_{i}$ identifies a context property of a grammatical feature $P_{i}$. The resulting language type can be defined as an array of parameter settings $\left\{\mathrm{P}_{\mathrm{i}}----\mathrm{P}_{\mathrm{i}}\right.$--$\left.-\mathrm{P}_{\mathrm{n}}\right\}$ on grammatical features. All the identified properties in context types and elements arise from a posteriori choices in acquisition. They are natural alternates, as there are natural alternates in making fire, setting up a family, or arranging fishing gear.

The longitudinal acquisition of Dutch is particularly clear on the points in (4) and each of these points is supported by a longitudinal acquisition graph (cf. Van Kampen 2006a). The data and percentages that support the five steps in Dutch are given for the child Sarah (CHILDES, Van Kampen corpus). This corpus will serve as the single point of orientation. ${ }^{2}$

\footnotetext{
2 The claims made in the present paper are based on the Sarah files only, but they are supported by longitudinal corpora from other children in CHILDES (Groningen corpus). It is my contention that the order of acquisition steps is a causal effect of massive daily input. The acquisition speed of children may differ, but it seems highly unlikely that there can be variation in the order of the steps themselves if these steps are shown to depend on each other (as in e.g. Van Kampen 2007).
} 
(4) Acquisition steps in Dutch

acquisition

point Sarah

1 proto-grammar $\quad \mathrm{V} 1 / \mathrm{V} 2$ parallel

(binary structures; no grammatical features)

$2 \mathrm{~V}<+$ fin $>$-to- $\mathrm{C}^{\mathrm{O}} \quad \mathrm{V} 1 / \mathrm{V} 2$ full parallel

3 subject obligation $\quad \mathrm{V} 1 / \mathrm{V} 2$ partial parallel

week 125

4 agreement and tense on $\mathrm{V}<+$ fin $>$

$\mathrm{V} 1 / \mathrm{V} 2$ parallel

week 132

5 Move $\mathrm{DP}< \pm$ wh $>$ to Spec.C

V1/V2 diverge

week 140

week 140

Child language in V1 Celtic and V2 Dutch are expected to be parallels in the first four steps. Thereafter, and fairly suddenly, they will start to differ. This may illustrate Jakobson's (1942) thesis that first language acquisition follows the pattern of a typological diversification.

The present paper will follow five acquisition steps in subsequent sections. Section 2 will deal with the fronting of the finite verb and pursue the perspective that this first acquisition step in V2 Germanic and V1 Celtic makes the two input types variants of the same basic structure. Section 3 will argue how the subject becomes obligatory only after $\mathrm{V}<+$ fin $>$ has been acquired. It will be subsequently shown why the subject obligation is better not derived from uninterpretable phi-features. Section 4 discusses the growing importance of Spec.C and the typological difference this will cause between V1 and V2 languages.

The successive acquisition steps indicate how grammar is built up in a flexible way (cf. Weerman 1989, Bury this volume, Koeneman this volume) by following, as I will argue, the typological properties of the input laid bare by input reduction (Van Kampen 1997).

\subsection{Typological assumptions}

The present paper proceeds from certain standard ideas about the typology of Dutch and of West-Germanic in general. A common analysis for West-Germanic generates all verbs in predicate-final position, typing Dutch as an SOV language. A root movement rule subsequently brings the finite verb into a clause-typing position labeled $\mathrm{C}^{\mathrm{O}}$ (Den Besten 1983). I further assume that the finite verb is an illocution marker and scope-bearing element (Wechsler 1991, Van Kampen 1997, Bayer 2004; but see Migdalski this volume). A standard idea is that $\mathrm{V}<+$ fin $>$-to- $\mathrm{C}^{0}$ movement is related to the scope properties of Tense (Evers 1981, 1982, Koeneman 2000, this volume). Showing that $< \pm$ tense $>$ oppositions only appear after the acquisition of V2, I will modify that idea and interpret $<+$ fin $>$ as the trigger for the $\mathrm{V}<+$ fin $>$-to- $\mathrm{C}^{0}$, where $<+$ fin $>$ is simply seen as the formal marking of an illocution unit (the root clause).

Consider the diagram in (5) and the examples in (6). $\mathrm{C}^{0}$ marks a prospective operator head and is defined as the first position c-commanding the predication IP/VP on the righthand side. The $\mathrm{V}<+$ fin $>$ in the $\mathrm{C}^{0}$ position can be preceded by a single constituent indicated as Spec.C. The Spec.C position is filled by a $\varnothing$ element, a turn-taker (nu 'now', dan 'then'), an adverb, or an aboutness phrase (unstressed subject, stressed topic phrase, wh-phrase). The initial XP aboutness phrase is typical for V2 languages. 
(5)

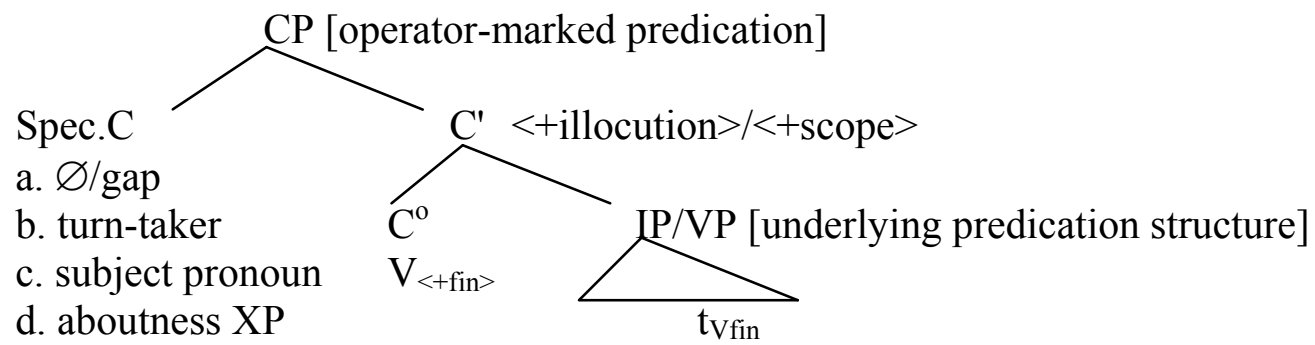

(6)a. gap

(dat) wil ik ook wel

'(that) want I also indeed'

(I would like that too)

b. turn-taker

nu moet het konijn slapen

'now must the rabbit sleep'

(the rabbit must sleep now)

c. unstressed subject pronoun

hij gaat slapen

'he goes sleep'

(he is going to sleep)

d. stressed aboutness phrase

vanavond moet het konijn gaan slapen

'tonight must the rabbit go sleep'

(the rabbit must go sleeping tonight)

All West-Germanic languages except English are V2 languages. Recently, Bury (2005) and Jouitteau (2005) have argued that languages like Breton and Welsh, traditionally typed V1 languages, are in fact V2 too. In affirmative declaratives a sentential particle precedes the $\mathrm{V}<+$ fin $>$. Breton and Welsh exhibit the same Move $\mathrm{V}<+$ fin $>$ to a sentenceinitial position, arguably clause-typing. They allow partly the same preverbal options, the $\varnothing$ elements and the turn-takers, be it that the range of these sentence-initial "particles" is wider in Celtic.

The assumption here is that Celtic V1 and Germanic V2 share the basic property of $\mathrm{V}<+$ fin $>$ in $\mathrm{C}^{0}$ as a clause-typing head. Yet, the differences in Spec.C options are also typologically relevant, be it that they are acquired later on. Consider the following utterances in child Dutch (Sarah, Van Kampen corpus in CHILDES, MacWhinney 2006).

(7) a. wil $k_{<+ \text {fin }>}$ ook hebben (Sarah 1;10.5, week 96)

'wanna also have'

(I-want to have (it) too)

b. is $<+$ fin $>$ Peter al

'is Peter already'

(Peter is already (there))

c. zit $_{<+ \text {fin }>}$ aapje op

'sit monkey on'

(Sarah 2;1.10, week 110)

(a monkey sits on (it)

(Sarah 2;3.16, week 119) 
d. moet $_{<+ \text {fin }>\text { papa doen }}$

(Sarah 2;3.16, week 119)

'must daddy do'

The sentence pattern [Aux/modal - (subject) - predicate] in (7) is typical for early Dutch child language. As will be shown in section $3.1,68 \%$ of the sentences with a finite verb in the speech of Sarah before the age of $2 \frac{1}{2}$ display this pattern. As one may realize, this is the Celtic V1 pattern. ${ }^{3}$

The underlying SOV order in Dutch and the $<+$ illocution $>$ operator $\mathrm{C}^{\mathrm{o}}$ interpretation in (5) are immediately supported by the acquisition facts, as first pointed out in De Haan (1987). All denotational verbs are first acquired as so-called optional infinitives, all (S)OV structures. The clause-typing appears in child language first by fixed copular and modal elements, whose nature as $<+\mathrm{V}\rangle$ elements is captured much later, but whose position as clause-initial constants is standard in early child Dutch. The acquisition of the Spec.C options follows the acquisition of the $\mathrm{V}<+$ fin $>$ movement. Subject pronouns and turn-takers come first (week 125), full aboutness phrases come later (week 140) (Van Kampen 1997).

\section{The acquisition of Move $\mathrm{V}<+$ fin $>-$ to- $^{0}$}

The acquisition of a structural property described by movement may seem paradoxical. Why should a language learning child bring in a structure $\mathrm{s} /$ he does not perceive to understand a structure she does perceive? The rule Move $\mathrm{V}<+$ fin $>$-to- $\mathrm{C}^{0}$ is probably the first, but fundamental, movement rule identified and mastered by the child. The system shows elaborate incremental preparations to induce this step (Van Kampen 1997, Wijnen 1997, Evers \& Van Kampen 2001, Blom 2003). The source and the target position of the movement are acquired separately. The $\mathrm{C}^{0}{ }_{<+f i n}>$ target position is identified by the acquisition of auxiliaries as clause-operators. The $\mathrm{V}^{\mathrm{o}}$ predicate head position is first acquired by so-called optional infinitive predicates.

\subsection{Before Move $V<+$ fin $>$-to- $C^{0}$ : the acquisition of Aux}

Productive child language starts with a radical and systematic reduction of the maternal input. Almost all grammatical features (functional categories) are left out. The utterances that remain consist at first of two denotational elements. Early child language exhibits a kind of 'proto-grammar' for simple pragmatic language games. The proto-grammar combines two lexical content (denotational) elements or it combines a pragmatic operator and a denotational element. There are no grammatical features involved. The denotational elements in this period do not carry by themselves a referential or a predicative intention, nor are they marked by some $\mathrm{I}^{\mathrm{O}}$ for predication or some $\mathrm{D}^{\mathrm{o}}$ for reference.

Early child language in Dutch starts with such a set of binary constructions (Van Kampen 1997), see (9) and (10). They are characterized by pragmatic functional labels in (8), because the parts of speech and their phrasal structure are still to be acquired.

\footnotetext{
3 The predominance of V1 patterns in child Dutch is reported in Yang (2002). The Dutch child Hein exhibits $50 \%$ of V1 patterns before the age of 3 (Groningen corpus CHILDES). See also Haegeman (1995). Yang argues that Dutch children start with a "Hebrew-type" of grammar.
} 
a. [topic-name + denotational comment] (illocutive intention presupposed)

b. [operator + denotational comment] (topic presupposed)

I assume that the topic element (the later subject) and operator element (the later $\mathrm{V}<+$ fin $>$ in $\mathrm{C}^{0}$ ) are still pragmatic elements. The examples in (9) relate pragmatically as topiccomment. The illocutive intention (statement, name-giving, wish, order) is presupposed here.

\begin{tabular}{lll}
\multicolumn{1}{l}{$\begin{array}{l}\text { topic } \\
\text { a. }\end{array}$ mamma } & comment \\
mummy & help \\
b. beer & bad \\
bear & bath \\
c. allemaal & nat \\
all & wet \\
d. wielletje & weg \\
wheel & gone \\
e. dat & beer \\
that & bear
\end{tabular}

Part of the utterances in (9) have been discussed as "optional (root) infinitives" in Wexler (1998). The cause of the phenomenon merits more attention. It is not a peculiar preference for non-finite structures, but follows from the child's general systematic reduction of grammatical features (cf. Lebeaux 1988, Radford 1990). The reductions can be seen as part of a decoding procedure: leave out temporarily all elements that you cannot sufficiently identify yet. Thereafter some reductions are overcome first and than others will follow in a predictable way.

The operator elements (10) indicate the pragmatic illocutive intention of the utterance (Van Kampen 2001, 2005), a wish, order, intention, statement. This "format" is typical for languages of the V1 and V2 type. It sets the stage for the later (syntactic) clausetyping property of $\mathrm{V}<+$ fin $>$-to- $\mathrm{C}^{\mathrm{o}}$.

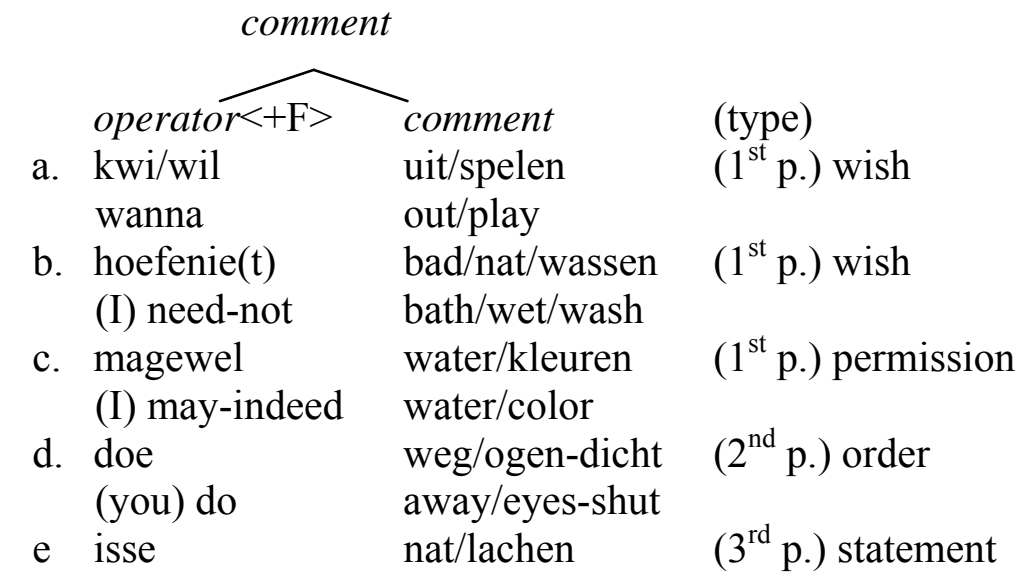



(it) is
wet/laughing
f. moet
weg/daar
$\left(3^{\text {rd }}\right.$ p.) requirement
(it) must
away/there
g. gaat
niet zo
$\left(3^{\text {rd }}\right.$ p.) intention
(it) goes
not this way

The adult source of these operator elements are the copula, the modal and the aspectual. These are quite frequent $(70 \%)$ in adult Dutch, the input for the acquisition procedure, as will be shown in section 2.2 (table in (16)). In the child's utterances in (10) the subject is implied. The operators for wish (wil/hoefenie) and permission (magewel) imply [I=speaker]. The operator expressing an order (doe) imply [you=addressee]. The operators for requirement (moet) and intention (gaat) and the operator expressing a statement (isse) do not imply the grammatical presence of speaker/addressee.

The use of the operator element reminds of the imperative in the adult language. Both the early operator and the later imperative are subject-implying moods. See Van Kampen (2004b, 2006b). It is at this acquisition stage not justified to label the operator elements in proto-grammar as $<+$ finite $>,<+$ copula $>,<+$ modal $>$ or $<+V>$. Such labels presuppose the presence of a morpho-syntactic system with categories, paradigms and phrase structure. All of that is still to be figured out by the child. I will define the utterance-typing operator as an underspecified category $<+F>$ (for finiteness), following Clahsen (1991). In a later acquisition stage $<+\mathrm{F}>$ will turn out to be $\mathrm{C}^{\mathrm{o}}$ when it appears regularly in all utterances and it need not define a subject configuration (Germanic, Celtic). In SVO languages where the finite verb does define a subject configuration (French, English), the category labeled $<+F>$ will later turn out to be $\mathrm{I}^{\mathrm{o}}\left(\mathrm{T}^{\mathrm{o}} /\right.$ subject $\left.\mathrm{AGR}\right)$.

The use of fixed operators becomes more frequent over time when three-word utterances add a topic in the operator-comment phrase (10), as in (11), or an operator to the topic-comment phrase (9), as in (12). The operators start to appear before or after the topic-name in three word utterances. Denotational verbs remain in the comment-final (sentence-final) position. The constructions in (11) and (12) are binary combinations of the constructions in (9) and (10). Other tree structures (binary or ternary) would not have been supported by the phrasals in $(9) /(10)$.

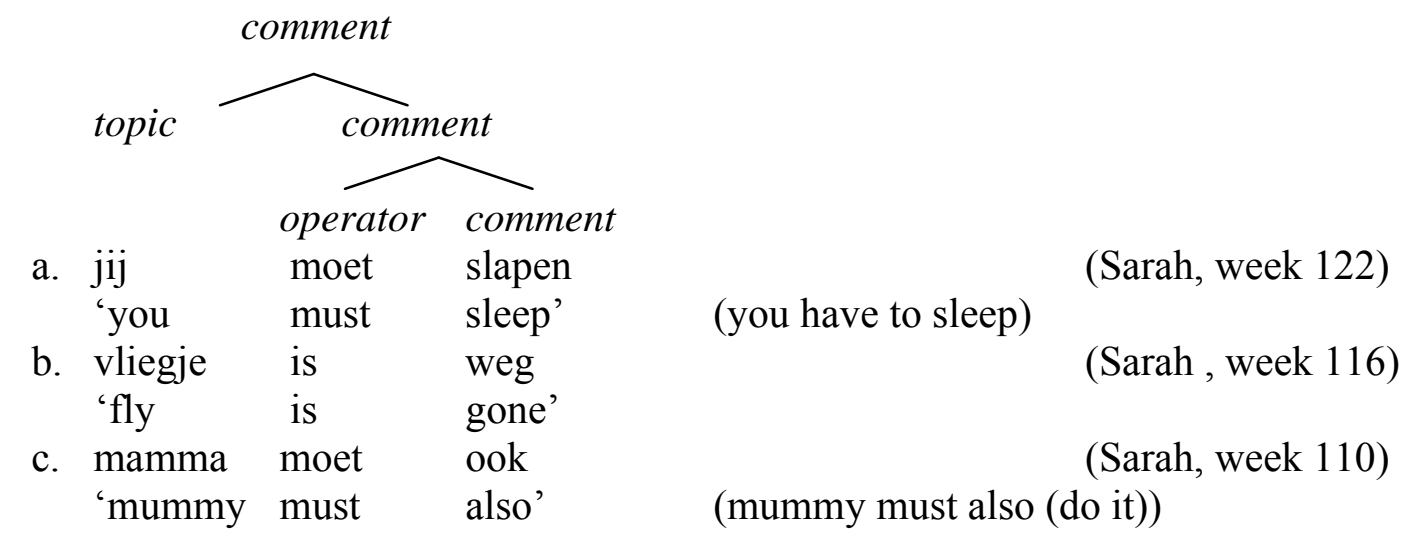


(12)

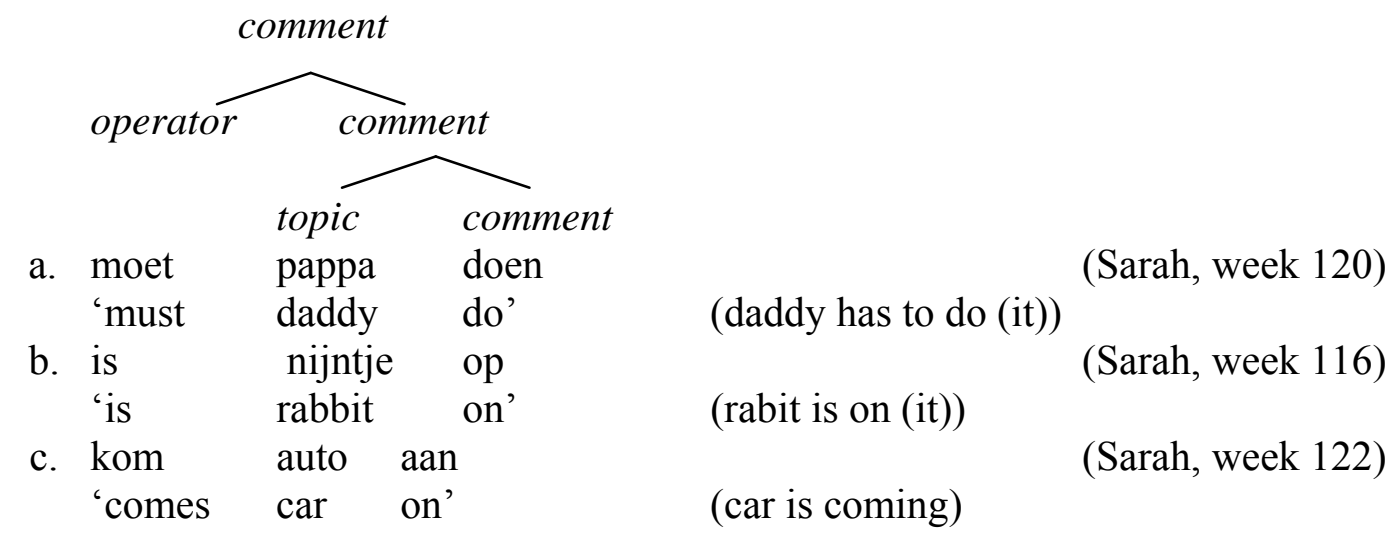

The operators in (12) are sentence-initial, just like the constructions reported in Borsley \& Morris Jones (2001) for the acquisition of Welsh, especially for the copula bod, in (13) the $3^{\text {rd }}$ person singular mae ('is').

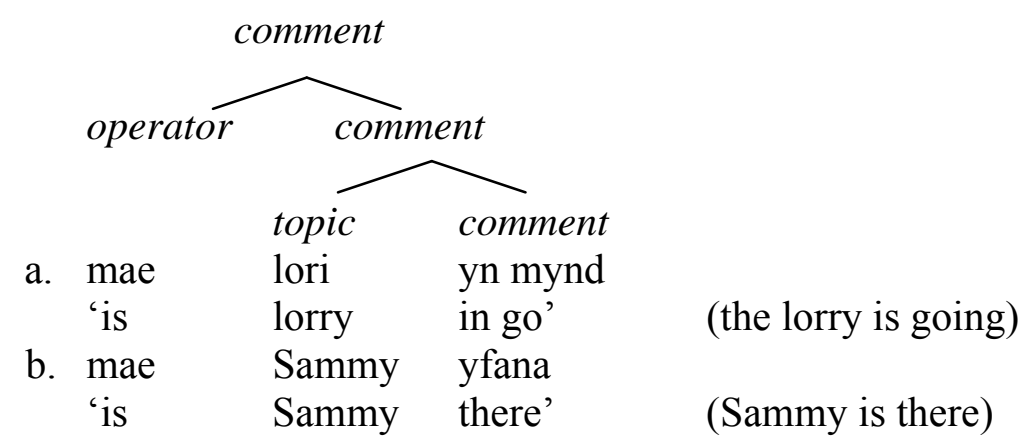

V1 and V2 languages share a high percentage of auxiliaries and semi-auxiliaries placed in front of and outside of a topic-comment unit, the patterns in (12) for Dutch and the ones in (13) for Welsh. The amount of auxiliary-based constructions is $>2 / 3(70 \%)$ of the maternal input. Denotational verbs are first acquired in clause-final $(<-$ fin $>)$ position.

\subsection{Move $\mathrm{V}<+$ fin $>$-to- $\mathrm{C}^{0}$ (the $\mathrm{V} 2$ graph)}

When more than $50 \%$ of the utterances appear with a standard modal operator marking, as in (14)a, a new development breaks in. Certain denotational elements in the comment part reappear with a morphological marking $<+$ fin $>$ in the operator position. They leave a corresponding gap in the comment part, as in (14)b.
a. (topic) [operator comment]
(ik) kannie zien
(Sarah 2;2.18, week 116)
'(I) cannot see'
((I) cannot see that)
b. denotational $\left.\right|_{<+ \text {fin }>}$ [topic comment gap] zie ik niet $\quad t_{\text {zie }}$ 'see ik not'
(Sarah 2;4.2, week 122)


The new, denotational, type (14)b is different. It is based on a gap. The gap-construction constitutes an important step. The gap and the positional opposition represent the awareness of pattern variation. The finite verb is the same lexical item as the non-finite verb. The lexical denotational item was marked as comment-final element before the distinction $< \pm$ fin $>$ applied. Rather than doubling the lexicon for $<+$ fin $>$ and $<-$ fin $>$ elements, the movement feature $<+$ fin $>\rightarrow<+C>$ expresses the categorial effect of the variation.

The rise of the $<+$ fin $>$ operators (14)a and $<+$ fin $>$ denotationals (14)b is reflected in the longitudinal graph in (15).

Dutch Sarah: rise of $<+$ fin $>$ marked predicates

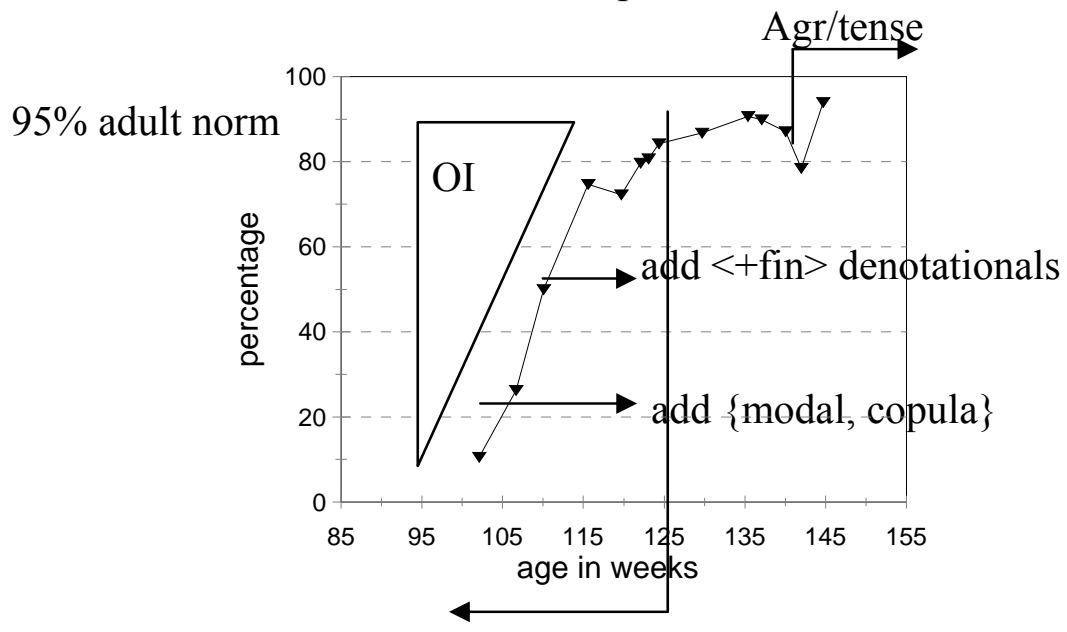

Left of the vertical in (15) (at week 125) are the "optional infinitives" (OI) and other nonfinite structures of proto-grammar. The rising $<+$ fin $>$ graph in (15) reflects how that type of structure fades out. The graph establishes the rising percentages of comments marked by $<+$ fin $>$ \{copula, modal, auxiliary, finite denotational\} in the speech of Sarah. Within 20 weeks (between week 105-125), the percentage rises from some $15 \%$ to more than $80 \%$ of the predicates marked. This is close to the level of the adult conversation, which was $93 \%$ in the speech of Sarah's mother.

Strictly speaking, the rise of \{modal, copula\} does not yet invite a Move $\mathrm{V}<+$ fin $>$-to$\mathrm{C}^{\mathrm{o}}$. It is still the operator element that has been present from the beginning on. The more immediate point is the awareness of the child that a (root) predication must have a grammatical marker, either a designated operator or a $<+$ fin $>$-marked element. The identification of all these modal operators as $<+\mathrm{V},+$ fin $>$ is a later development. The rise of finite denotationals, though, does signal the introduction of a syntactic category $<+\mathrm{V}>$. There appears to be a set of lexical elements that allows the variation $<+f$ fin $>\mid<-$ fin $>$. That set is $<+\mathrm{V}>$. The label $<+\mathrm{V}>$ is also a departure from the pragmatic labels of 'protogrammar'. The category $<+\mathrm{V}>$ is well-defined by a morphological paradigm and its two corresponding syntactic functions. The morphological $\mathrm{V}<+$ fin $>$-marking corresponds with the clause-initial syntactic marking of "illocution" and the morphological $\mathrm{V}<-$ fin $>$ marking corresponds with the syntactic functions of defining the "comment" in clausefinal position. The comment can now be defined as that part of the utterance that requires the gap $t_{V}$ and the extended comment is now characterized by the pre-posed $\mathrm{V}<+$ fin $>$. 
The percentage of sentences with a verb that is a finite denotational rises to the adult level of $30 \%$ in less than half a year (Van Kampen 1997). This is shown by the table in (16) (from Evers \& van Kampen 2001).

Rise of the denotational V<+fin>-to- $\mathrm{F}^{\mathrm{o}}(25$ weeks $)$
\begin{tabular}{|l|l|l|l|l|}
\hline Age in weeks & $\begin{array}{l}\text { Sarah } \\
107-110\end{array}$ & $\begin{array}{l}\text { Sarah } \\
115-122\end{array}$ & $\begin{array}{l}\text { Sarah } \\
129-133\end{array}$ & $\begin{array}{l}\text { Mother } \\
\text { (constant) }\end{array}$ \\
\hline modal/auxiliary & $92 \%$ & $80 \%$ & $70 \%$ & $70 \%$ \\
\hline denotational V & $\begin{array}{l}8 \% \\
\text { eureka point }\end{array}$ & $20 \%$ & $\begin{array}{l}30 \% \\
\text { acquisition point }\end{array}$ & $30 \%$ \\
\hline
\end{tabular}

The first three columns present Sarah's <+fin $>$ marking by means of auxiliaries/modals versus denotational verbs in the beginning, the middle and just after the end of the 20 weeks period of the V2 acquisition curve in (15). ${ }^{4} \mathrm{~A}$ trend-setting column for the mother has been added, set on 1000 consecutive V2 utterances. The table in (16) shows that only after the acquisition of V2 at week 125, the percentage of finite denotational verbs is at the adult level. It is also at this period (week 129-133) that the subject becomes obligatory as will be shown in the next section.

The appearance of the denotational $\mathrm{V}<+$ fin $>$ in the initial operator position invites the Move $\mathrm{V}<+$ fin $>$ switch. The alternative would be to have two entries in the lexicon $\mathrm{V}<-$ fin $>$ for the construction [operator ----V $<-$ fin $>$ ] and $\mathrm{V}<+$ fin $>$ for $[\mathrm{V}<+$ fin $>----$ [XP gap]. If the system were based on a doubled lexicon, as assumed in non-movement systems like Categorial Grammar, one might as well expect languages where the lexical doublets $<+$ fin/-fin $>$ were phonologically unrelated as well, as now often holds for the copula (e.g. the English paradigm am/is/are versus been/be). If the new variant is seen as a movement result, the lexicon need not be doubled over $\mathrm{V}< \pm$ fin $>$ and a predicate-final gap $t_{\mathrm{V}<+ \text { fin }}>$ is natural.

The graph in (15) above reflects the rise of Move $\mathrm{V}<+$ fin $>$-to- $\mathrm{C}^{0}$. From a point just below $60 \%$ denotational verbs may appear clause-initial as $<+$ fin $>$ and clause-final as $<-$ fin $>$. At the V2 acquisition point (week 125), 19 verb types (23\%), have shown a $<+$ fin $>/<-$ fin $>$ overlap in the Sarah files. At week 133, the percentage of denotational finite verbs has reached the adult level, see (16) above, and the $< \pm$ fin $>$ overlap for denotational types reaches the adult level, around 25\%..$^{5}$ It may be objected that the files show no more than a couple of denotationals that appear as $<+$ fin $>$ and $<-$ fin $>$. However, one should not forget that the files represent a (regrettably) small fraction of the actual maternal input and child production (less than 1\%). The recordings took place 45 minutes every two weeks. The number of denotational verbs in the input is to be multiplied by, say, 112 (8x14). So each day any denotational had a chance to appear <+fin $>$ and $<-$ fin $>$. 6

\footnotetext{
${ }^{4}$ The following files were selected: files 9,10: $86 n-7 n=92 \%-8 \% ; 11-13: 140 n-36 n=80 \%-20 \% ; 17-19: 297-$ $127=70 \%-30 \%$. Imperatives and subordinates were left out. Of course, the percentages are based on a lower number of utterances for the first files than the percentages for later files.

${ }^{5}$ The adult percentage of $25 \%$ was counted for the mother of Sarah in file 19, at Sarah's week 133.

${ }^{6}$ Albeit with the following restriction. Some verbs, especially action verbs are used more often $<-$ fin $>$ than $<+$ fin $>$.
} 
So far, I have spoken about $\mathrm{V}<+$ fin $>-$ to- $\mathrm{C}^{0}$. Strictly speaking, the position of $\mathrm{V}$ $<+$ fin $>$ has not yet been analyzed as $\mathrm{C}^{0}$ by the acquisition procedure. A decision $\mathrm{F}^{\mathrm{o}} \Rightarrow \mathrm{C}^{\mathrm{o}}$ still has to be made. The decision depends on the (later) development of the subject obligation. If Spec.F is used for the external argument only, $<+$ fin $>$ is reinterpreted as $\mathrm{I}^{\mathrm{o}} / \mathrm{T}^{\mathrm{o}}$ (French, English). Otherwise it becomes $\mathrm{C}^{\mathrm{o}}$ (Germanic, Celtic). Fortunately, the development of subject obligation can be captured by means of an acquisitonal graph as I will show now.

\section{The acquisition of the subject obligation}

There is a subject obligation for nearly all Germanic predicates. Yet, the acquisition of the subject obligation is a problem in Germanic V2. The learner is not confronted with a steady overt subject configuration. This is due to the immediate appearance and frequency $(50 \%)$ of subject-finite verb inversions $(\mathrm{V}<+$ fin $>$-Subject). Nevertheless, the subject obligation is acquired in a step following the acquisition of finite verb movement. That is the good news. The bad news is that an EPP based on tense or uninterpretable phifeatures on the finite verb plays no part in the acquisition of subject formation. The correct use of tense $< \pm$ past $>$ and phi-features $< \pm$ number, $\alpha$ person $>$ on the finite verb appear well after the acquisition of the subject obligation (pace Schütze \& Wexler 1996). Although, it is not crystal clear how and why the acquisition procedure is bound to establish the subject obligation, the irrelevance of uninterpretable phi-features is. This is encouraging news for the learnability of languages that have the subject obligation, but no phi-features at the finite verb (Scandinavian languages, Afrikaans, English dialects). The subject requirement is plausibly something more general than phi-marking and I prefer to concentrate on its identity in spite of typological variations in position and agreement marking.

\subsection{The quantitative correlation $<+$ fin $>\mid<+$ subject $>$}

When $\mathrm{V}<+$ fin $>$-to- $\mathrm{C}^{\mathrm{O}}$ has reached the acquisition point at week 125 (see (15)), a new development sets in. The 'topic' that was optional in the binary proto-grammar, tends to appear in most of the constructions $\mathrm{F}^{\mathrm{o}}=\mathrm{V}<+$ fin $>$. 'Topic' continues to appear in front of the $\mathrm{V}<+$ fin $>$ or immediately after it. These two positions were already established in the child's proto-grammar (cf. (11)/(12)). The trend of mentioning the topic fits the adult input, although at week 125 Sarah's modals, not yet analyzed as $<+$ fin $>$, still have the subject/topic implied, as I will show below. I will first give the quantitative distributions for subject/topic in the adult language. Subsequently the quantitative distribution in the speech of Sarah will be shown.

The quantitative distributions in the adult input for Spec.C and subject/topic are given in (17). In V2 Dutch the subject may either precede the finite verb (in Spec.C) or the subject may follow the finite verb when the Spec.C is filled with a non-subject. 
(17) Adult Dutch (input for child) for Spec.C and subject:

Relative $\%$ of all declarative $\mathrm{V}<+$ fin $>$ sentences (out of 537)

\begin{tabular}{|c|c|c|c|c|}
\hline & $\begin{array}{l}\text { Subject-Vfin } \\
(\text { Spec.C = subject })\end{array}$ & $48 \%$ & $\begin{array}{l}10 \% \\
38 \%\end{array}$ & $\begin{array}{l}\text { subject full DP } \\
\text { subject pronoun }\end{array}$ \\
\hline b. & $\begin{array}{l}\text { Non-subject-Vfin-Subject } \\
\text { (Spec.C = non-subject) }\end{array}$ & $30 \%$ & $\begin{array}{l}10 \% \\
20 \%\end{array}$ & $\begin{array}{l}\text { non-subject full DP } \\
\text { non-subject pronoun/dummy }\end{array}$ \\
\hline & $\begin{array}{l}\text { Vfin-Subject } \\
\text { (empty Spec.C/no Spec.C) }\end{array}$ & $18 \%$ & $\begin{array}{l}4 \% \\
14 \%\end{array}$ & $\begin{array}{l}\text { topic-drop } \\
\text { narrative inversion }\end{array}$ \\
\hline & $\begin{array}{l}\text { Vfin (no subject) } \\
\text { (no Spec.C) }\end{array}$ & $4 \%$ & & \\
\hline
\end{tabular}

The percentages in (17) are calculated for the adult conversation partner (the mother) in the Sarah files (files 07-11; Sarah's weeks 100-116). The percentages in (17) show that the Spec.C need not be present $(22 \%$, see $(17)$ c,d), in contrast to the subject which is almost always (96\%) present. As one may also see in (19), the subject may precede (48\%, (17)a) or follow $(48 \%,(17) \mathrm{b}, \mathrm{c})$ the finite verb in $\mathrm{C}^{\mathrm{o}}$. This spells out an interesting acquisition problem. The subject is obligatory present, but the acquisition procedure should abstract away from a specific configuration (Spec.C or Spec.IP)

The acquisitional question is now, what does the child make of the input in (17) and why does she do so? A count of sentence-initial Spec.C and subject-presence in the speech of Sarah yields the percentages in (18).

(18) Child Dutch during the acquisition of $\mathrm{V}<+$ fin $>-$ to- $\mathrm{C}^{0}$ (between weeks 107-125)

Relative $\%$ of all declarative $\mathrm{V}<+$ fin $>$ sentences (out of 595)

\begin{tabular}{|c|c|}
\hline a. Subject-Vfin & $\begin{array}{|lll|}\mathbf{2 8 \%} \% & 6 \% & \text { subject noun } \\
& 22 \% & \text { subject pronoun } \\
\end{array}$ \\
\hline b. Non-subject-Vfin-Subject & (all turn-takers) \\
\hline c. Vfin-Subject & $17 \%$ \\
\hline d. Vfin (no subject) & $51 \%$ \\
\hline
\end{tabular}

Although (18) averages over the 18 weeks that precede the V2 acquisition point (week 125), there is no significant shift in the quantitative relations between (18)a, (18)b, (18)c, and (18)d. Only the percentage of the $\mathrm{V}<+$ fin $>$ construction grows, as indicated in the rising curve of (15). The quantitative relation between the subtypes (18)a,b,c,d is stable.

The child's output for the presence of a subject corresponds with the mother's input on three points.

a. In as far as the construction is carried by a $<+$ fin $>$ denotational in $\mathrm{C}^{0}$ (and a corresponding $t_{V}$ in predicate-final position), there is a subject present in (almost) all cases.

b. The $<+$ fin $>$ conditioned subject may appear in Spec.C or in inversion almost according the fifty//fifty division $(28 \% / 21 \%)$

c. The relation between pronominal subjects and non-pronominal subjects (4:1) matches the input from the beginning on. 
Hence, there is subject obligation for the $<+$ fin $>$ denotational verbs in $\langle+F\rangle$, but there is no subject configuration such that Spec. $<+\mathrm{F},+$ fin $>$ simply is the subject. Roughly half of the subjects $(21 \%)$ follow and half of the subjects $(28 \%)$ precede the $V<+$ fin $>$ in the speech of Sarah.

The difference between the mother's input and the child's output is no less striking.

(20) Absence of the subject (51\%, see (18)d), is quite common. This is mainly due to the modal operator constructions that still maintain their mood-implied subject orientation.

Some of such subject-less modals in Sarah's speech are exemplified in (21).
a. kwi nog rijs(t)ewafel
'(I) wanna still rice-cracker'
(I want another rice-cracker)
b. moet annersom
'(it) must around'
(it must go the other way around)
c. kannie op zitten
'(I) cannot on sit'
(I cannot sit on it)
d. maggenie dit opeten
(you may not eat this (=the drink))
'(you) may not this up-eat'
(Sarah week 123)
(Sarah week 123)
(Sarah week 125)
(Sarah week 128)

The main points so far are the close association between the denotational $\mathrm{V}<+$ fin $>$ and the presence of the subject, cf. (19), whereas the modal operators still tend to stick to the absence of the subject, cf. (20).

The 7 weeks that follow the acquisition point of the V2 rule show a (dramatic) shift towards subject obligation. Root sentences that lack an explicit subject, drop from over $50 \%$ to less than $5 \%$ and confirm to the adult norm of $96 \%$ thereafter, see (22).

(22) Child Dutch after the acquisition of $\mathrm{V}<+$ fin $>$ (week 125 and after)

Relative $\%$ of subjects in $\mathrm{V}<+$ fin $>$ sentences

\begin{tabular}{|l|l|l|l|}
\hline Age & $\%$ full subject & $\%$ clitic subject & $\%$ subject \\
\hline week 125 & $42 \%$ & $5 \%$ & $\mathbf{4 7 \%}$ \\
\hline week 128 & $68 \%$ & $11 \%$ & $\mathbf{7 9 \%}$ \\
\hline week 129 & $71 \%$ & $8 \%$ & $\mathbf{7 9 \%}$ \\
\hline week 132 & $88 \%$ & $8 \%$ & $\mathbf{9 6 \%}$ \\
\hline week 133 & $84 \%$ & $12 \%$ & $\mathbf{9 6 \%}$ \\
\hline
\end{tabular}

What obviously happens is a reinterpretation of the modal operators as $<+$ fin $>$ verb, the type of element that invokes the obligatory presence of the subject. 
The development in (22) is given in graph B in (23). Graph A in (23) repeats the graph in (15) for the acquisition of a shared root clause operator $<+F>$, either a $<+$ fin $>$ denotational or a modal operator.

(23) Dutch Sarah: acquisition of $<+$ fin $>$ and subjects

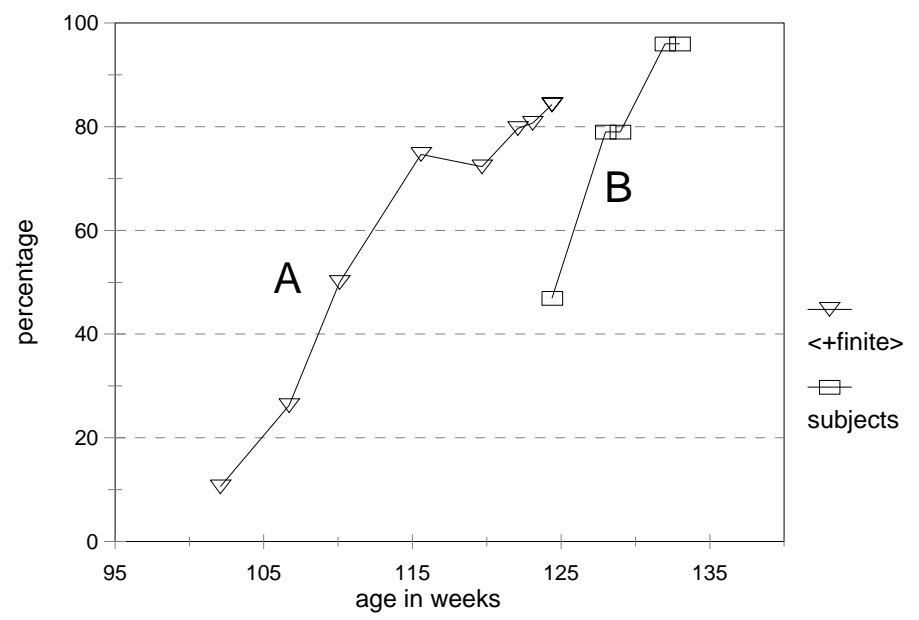

The subject obligation for modal operators (graph B) lags 7 weeks behind. The fact is there. Plausibly, it may be interpreted as follows. The modal elements that preferred mood-implied subjects are an inheritance from the binary constructions in proto-grammar (cf. (10). The adult input nevertheless shows real subjects as if these modals were simply $<+$ fin $>$ elements. Consequently, they are reinterpreted that way as soon as the acquisition procedure established the initial pattern: $\mathrm{V}<+$ fin $>\Leftrightarrow$ subject, at week 125 . The subject presence pushes the modal operators into a $<+$ fin $>$ status. Their subjects, so far an optional and somewhat marginal affair, are from thereon a grammatical obligation.

What we still need is an acquisition procedure that guides the $<+$ fin $>$ constructions toward the subject obligation. Once that procedure is on its way, the modals will follow.

\subsection{An acquisition frame}

The subject in Spec.C is definite and may have a kind of sentential aboutness function. The Spec.C position brings the subject in a conventional specifier-head relation with the $\mathrm{V}<+$ fin $>$ in $\mathrm{C}^{\mathrm{o}}$. However, this covers but half of the subject-finite verb constructions. The subjects following the $\mathrm{C}^{0}$, the other half of the cases, are obviously not in a specifier relation with the $\mathrm{V}<+$ fin $>$ in $\mathrm{C}^{0}$. Hence, the subject is obligatory with $\mathrm{V}<+$ fin $>$, but there is no subject configuration such that Spec. $<+$ fin $>$ simply is the subject.

An order "find yourself a subject for each $\mathrm{V}<+$ fin $>$ " cannot be the most convincing form for guiding the acquisition procedure towards a subject obligation. For that reason, I propose provisionally the format in (24). Let the feature $<+$ fin $>$ be associated with the context feature in (24). 


$$
\begin{aligned}
& <+ \text { fin }> \\
& <*\left[D^{o}[--------]_{\text {context }}\right]>
\end{aligned}
$$

The problem has now been shifted towards an acceptable label for "context". A context label that excludes that the subject reference could be VP and a label that includes it could be vP. This of course is not yet an acquisional account. If there is no element $\mathrm{D}^{\mathrm{o}}$ in the appropriate context, the * added to the new feature will cause ungrammaticality. If there is such an element $\mathrm{D}^{\mathbf{o}}$ in the appropriate context, the context feature and its * will be removed. This is to express the fact that the subject expectation now associated with $\mathrm{V}<+$ fin $>$ got satisfied. I take (24) as the basic form of Agree for subjects, and also as a format to acquire the agreement relation.

The label $\mathrm{D}^{\circ}$ in (24) stands for a list of elements with a referential function. Around week 120, Sarah starts using $3^{\text {rd }}$ person pronouns hij/zij/het ('he'/'she'/'it') and articles are added to nouns. ${ }^{7}$ The articles carry in principle the opposition definite (mentioned previously or presupposed in discourse) versus indefinite (newly introduced in discourse). Articles and $3^{\text {rd }}$ person pronouns are $\mathrm{D}^{\mathrm{o}}$-elements with a discourse-bound reference rather than a situation-bound reference. The acquisition point of the development of articles for Sarah is week 145. This development is given in graph C. Graph $\mathrm{D}$ is added for the rise of $3^{\text {rd }}$ person pronouns in the speech of Sarah. Both graphs are taken from Van Kampen (2004c). Graph B in (25) repeats the graph in (23) for the rise of subject obligation.

Dutch Sarah: acquisition of subjects, determiners and $3^{\text {rd }}$ person pronouns

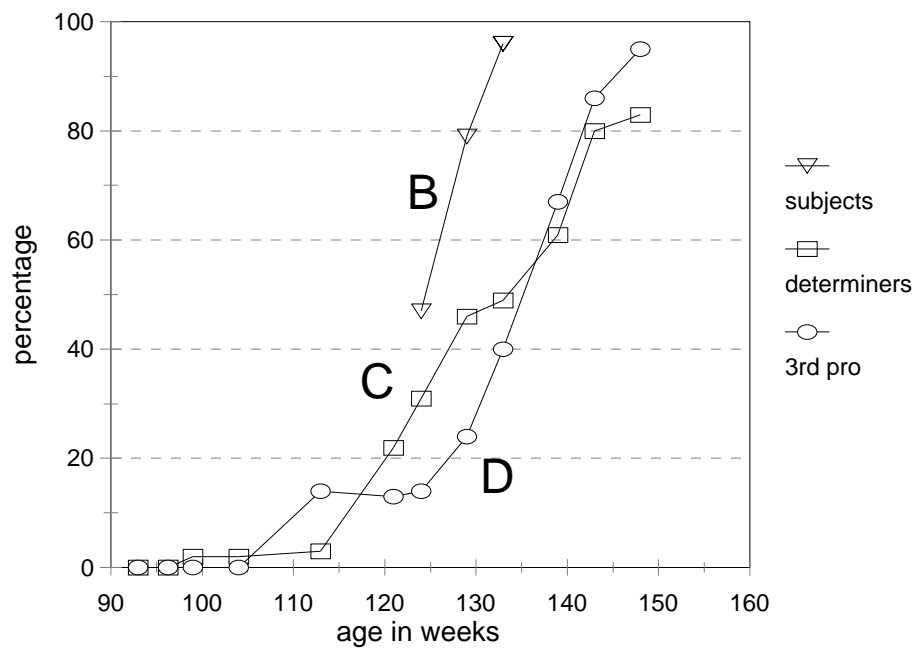

The reference marking for the subject (graph B) seems to run ahead of $\mathrm{D}^{\mathrm{o}}$-marking in general $\left(< \pm\right.$ definite $>$ determiners, $3^{\text {rd }}$ person pronouns). The subject obligation that reaches its acquisition point at week 132 (graph B) needs the referential marking mentioned in (24). Such marking is in principle only available for half of the cases according to graph C (49\% at week 133). This fact needs further scrutiny. Remember,

\footnotetext{
7 Before week 125, the child only uses nouns and pronouns with situation-bound deictic reference, like stressed demonstratives, first and second person pronouns, and nouns used as quasi proper names.
} 
though, that initially full subjects nouns are rare in the speech of Sarah, and if present they are mostly proper nouns.

The difficult point for (24) is the specification of the context condition. For the time being, I propose VP as the label acquired for the lexical frame of a denotational verb and VP for the same frame extended or enhanced by <+fin $>$. The VP has already been encoded in the lexicon when the verb was acquired (in the proto-grammar). If a referential element $\mathrm{D}^{\mathrm{o}} / \mathrm{DP}$ is added to the completed VP frame, it allows an interpretation as subject and will remove the $*$ in the $\mathrm{V}<+$ fin $>$. If no such $\mathrm{D}^{\circ} / \mathrm{DP}$ element is added to the $\mathrm{VP}$ frame, the $\mathrm{V}<+$ fin $>$ will move into the position $\mathrm{C}^{\mathrm{o}}$. The $*$ can now be removed by adding the $\mathrm{D}^{\mathrm{o}} / \mathrm{DP}$ in the Spec.C. Otherwise the construction will remain ungrammatical. This arrangement will work for the present stage of child language. There is more to subject obligations and subject positions when dummy subjects, indefinite subjects and non-finite predicates are considered, but I must leave this for further research. The context DP [ --- $\mathrm{V}<+$ fin $>---]_{V P}$ may work for the cases at hand. Fortunately, the CP is a $\mathrm{V}$-projection after the $\mathrm{V}<+$ fin $>$ has moved into $\mathrm{C}^{\mathrm{o}}$. Hence the removal of the ${ }^{*}$ will also work if the addition/merge of the subject is delayed until the Spec.C. Due to this move (a delayed merge of the subject), the acquisition procedure needs not construct a subject movement into Spec.C.

An underlying assumption of this entire consideration is that the $t_{V f i n}$ is an active factor in the construction. Striking evidence that $t_{v<+ \text { fin }}$ is an active factor comes from the acquisition of subordinates.

Finite subordinate clauses in Dutch differ from root clauses by having the $\mathrm{V}<+$ fin $>$ in a predicate-final position. They constitute no more than about $2 \%$ of the maternal input. Hence, they must appear as nearly unlearnable, when $98 \%$ of the $<+$ fin $>$ constructions demonstrate V2. Yet, as often the facts insult common sense. Sarah's first subordinate clauses appear in week 135 and seem to offer no problem as to the verbal positions. She acquires the subordinate order instantaneously, as if she 'knew' the underlying structure all along. The instantaneous acquisition is explained if one assumes that the initial representation of predicate structure as verb-final in the 'optional (root) infinitives' stage is retained in the lexicon, and being lexically encoded implies that the encoding is irreversible. Hence, $\mathrm{V}<+$ fin $>$-to- $\mathrm{C}^{\mathrm{o}}$ in root predication is and remains derived from the predicate-final position. If this rule $\mathrm{V}<+$ fin $>-$ to- $\mathrm{C}^{\mathrm{O}}$ is blocked, the subordinate appears as a simplification of the root clause pattern, rather than a contradiction of it.

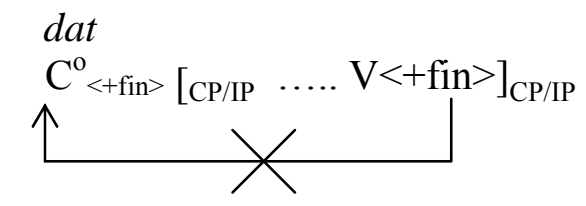

At first, the acquisition procedure is still hesitant about the complementizer constants that introduce the subordinate, but immediately oriented at the predicate-final position of the finite verb, see Sarah's examples in (27).
a. ik wil niet $\varnothing$ (je) even mij met kringetjes maak $<+f i n>\quad$ (S. week 135) 'I want not $\varnothing$ (you) just me with circlets make < fin $>$ ' (I do not want you to make circlets with me)


b. dat zijn twee kindertjes $\varnothing$ in de water speelt $<+$ fin $>$
'that are two children $\varnothing$ in the water play $<+$ fin $>$

(S. week 142)

(that are two children that play in the water)

Observe how the structure of the subordinate is further simplified by leaving out in the subordinate: the complementizer constant in (27)a, the relative pronoun in (27)b, the subject pronoun in (27)a, and the verbal phi-agreement in (27)b. The predicate-final position of the finite verb, by contrast, is immediately positioned as predicate-final.

\subsection{The late acquisition of subject-verb phi-agreement}

Format (24) for subject obligation in the context of finite verbs works without subjectverb phi-agreement. Much attention is paid to the reasons and the mechanics for phifeature distribution in the present-day Minimalist theory of clauses. See Rouveret (this volume, example (11)) for the options this may offer in comparative grammar. Much to my regret, I have to report that such concerns (phi-agreement and typological effects) get little confirmation from the present acquisitional approach. Consider the following two circumstances. (i) The actual state of subject-verb phi-agreement in non pro-drop languages as Dutch, French and English is restricted to the present tense and close to nil. (ii) The acquisition point for subject-verb phi-agreement is late. The relatively late acquisition of verbal phi-agreement had already been noticed for German in Clahsen (1991). In contrast to Dutch, German has a fairly "rich" person agreement, but that made no difference for the phi-agreement delay.

The empirical evidence for phi-agreement in the Sarah files is clear enough. Sarah's verbal phi-agreement appears in week 140-142, 15 weeks after the V2 acquisition point (week 125), 10 weeks after the first appearance of plural subjects, and still 8 weeks after the full effect of the obligatory subject at week $132 .{ }^{8}$ The late rise of verbal phiagreement is supported by the numbers in (28) (from Van Kampen 2006a).

Child's verbal phi-agreement

\begin{tabular}{|l|l|l|}
\hline Age in weeks & $130-135$ & $140-142$ \\
\hline + plural subject & 12 & 13 \\
\hline *no agreement & $* 7$ & $* \mathbf{0}$ \\
\hline agreement & 5 & 13 \\
\hline
\end{tabular}

Dutch person agreement is not rich, but number agreement in the present tense is a consistent $\mathrm{V}[\mathrm{stem}+-e n]$. Therefore, I take $< \pm$ plural $>$ as major verbal phi-agreement distinction (see also Hoekstra \& Hyams 1998). Before the acquisition of verbal phiagreement, the child marks only the opposition $<+$ fin $>$ (slaap 'sleep') versus $<-$ fin $>$ (slapen 'sleep') marked by positional oppositions.

The verbal phi-agreement comes in at week 140, eight weeks after the acquisition of the subject obligation at week 132 . This characterizes verbal phi-agreement as too late to

\footnotetext{
${ }^{8}$ Some may feel that ten weeks is not that much difference and after all how much is much? I would like to follow here the recommandation in Briscoe (2000). One should strictly speaking not think in weeks, but in the amount of child-directed clauses and child-produced clauses. If we assume some modest 3000 clauses a day, the ten-week period amounts to $10.7 .3000=210.000$ elementary exercises before the pattern is acquired.
} 
be relevant to the subject obligation in Dutch, and probably more general in all Germanic V2 grammars. An example of a plural subject at week 130 is given in (29)a and an example at week 140 is given in (29)b. a. $* \frac{\text { de clowntjes }}{\text { the clownies }}<+$ plural $>\frac{\text { heb }}{\mathrm{has}}<+$ sing $>\quad \begin{aligned} & \text { oogjes } \\ & \text { eyes' }\end{aligned}$
(Sarah week 130) (the little clowns have eyes)
b. $\sqrt{ }$ wij $<+$ plural $>$ zitten $<+$ plural $>$ in badje (we are sitting in bath)
(Sarah week 140)

The following may be noticed. Up till now I have argued that $<+\mathrm{F}>$ will turn out to be $\mathrm{C}^{\mathrm{O}}$ when it appears regularly in all utterances and it need not necessarily define a subject configuration in V2 Dutch. I have not been able to provide the acquisition procedure with a stimulus to construct a separate projection IP/TP. It seems impossible to get evidence for VP and IP/TP as two simultaneous, but separate projections. Rather than IP/TP, I would like to join the learnability position advanced in Watanabe (1994) that if the positions of the finite verb and the non-finite verb are always string-adjacent, the language acquisition procedure cannot gain information about a rule $\mathrm{V}$-to- $\mathrm{I}^{\mathrm{O}} / \mathrm{T}^{\mathrm{o}}$. This recaptures from an acquisitional point of view the thesis "IP=VP" in Weerman (1989), as elaborated in Van Kampen (1997). Note that it is a curious property of adult grammars that the functional categories $\mathrm{C}^{\mathrm{o}}$ and $\mathrm{I}^{\mathrm{O}}$ have an "either/or" condition on their spell-out. They are never spelled-out both. This either/or for separate labels asks for an explanation that offers more than a fortunate derivational outcome.

If one were to see language acquisition as a mere fill-in exercise on the multiple IP left branch cartography (already spelled-out for the learner due to innate cognitive intuitions), one may fail to explain why subject-verb phi-agreement step (30) (v) follows on the previous acquisitional steps (30) (i), (ii), (iii) and (iv).
a. (i) Move $\mathrm{V}<+$ fin $>$-to- $\mathrm{C}^{0}$ and get the $t_{\mathrm{Vfin}}$ in predicate-final position (week 125)
b. (ii) Add the external argument to each $\mathrm{V}<+$ fin $>$ construction (week 132)
c. (iii) generalize over $<+$ Modal $>$ operator and $\mathrm{V}<+$ fin $>$ (week 125-132)
d. (iv) Add $\mathrm{D}^{\circ}< \pm$ number $>$ to all arguments (week 120-140)
e. (v) Copy $<+$ number $>$ to $\mathrm{V}<+$ fin $>$ from its external argument (week 140).

All these steps have been identified by longitudinal acquisition graphs and have been reconstructed as building-up the context relevant for phi-agreement. .

\section{The acquisition of Spec.C. Where Germanic differs.}

When Sarah reaches the acquisition point for the $\mathrm{V}<+$ fin $>-$ to- $^{0} \mathrm{C}^{0}$ movement at week 129, she is still close to a V1 type of grammar. The finite verb is not preceded by anything, see the table in (31), a combination of the tables in (17) and (18) (section 3.1) for Sarah and her mother. 
(31) Spec.C in the speech of Sarah and her mother

\begin{tabular}{|c|c|c|}
\hline Type & Sarah week 107-125 & Mother \\
\hline a. Subject-Vfin & $\begin{array}{l}\mathbf{2 8 \%} \\
6 \% \text { subject NPs/DPs } \\
22 \% \text { subject pronouns }\end{array}$ & $\begin{array}{l}\mathbf{4 8 \%} \\
10 \% \text { subject full DPs } \\
38 \% \text { subject pronouns }\end{array}$ \\
\hline b. Non-subject-Vfin-Subject & $\begin{array}{l}4 \% \\
\text { turn-takers }\end{array}$ & $\begin{array}{l}\mathbf{3 0 \%} \\
10 \% \text { non-subject full DPs } \\
20 \% \text { turn-takers }\end{array}$ \\
\hline $\begin{array}{l}\text { c. Vfin-Subject } \\
\text { (no Spec.C) }\end{array}$ & $\begin{array}{l}\mathbf{1 7 \%} \\
\text { narrative inversion }\end{array}$ & $\begin{array}{l}\mathbf{1 8 \%} \\
4 \% \text { topic-drop } \\
14 \% \text { narrative inversion }\end{array}$ \\
\hline $\begin{array}{l}\text { d. Vfin (no subject) } \\
\text { (no Spec.C) }\end{array}$ & $\begin{array}{l}\mathbf{5 1 \%} \\
\text { mood-implied subject }\end{array}$ & $\begin{array}{l}\mathbf{4 \%} \\
\text { mood-implied subject }\end{array}$ \\
\hline
\end{tabular}

In $72 \%$ of the clauses, the finite verb is not preceded by anything (68\%), or just by a turntaker (4\%), see (31)b,c,d. A subject/topic argument may precede the finite verb, but these are nearly all, almost $80 \%$, subject pronouns.

Lack of a Spec.C in the adult input was $22 \%$, see (31)c,d, whereas $20 \%$ of the clauses had the finite verb preceded by a turn-taker, see (31)b. The constructions that lack a Spec.C in adult Dutch are subdivided as in (32).
No overt Spec.C
a. narrative inversion
$(\mathrm{V}<+$ fin $>$-subject $)$
$14 \%$
b. topic-drop
$(\varnothing \mathrm{V}<+$ fin $>$-subject $)$
$4 \%$
c. subject-drop
$(\mathrm{V}<+$ fin $>($ no subject $)) \quad 4 \%$

The option of a non-realized Spec.C is never used in the written language, but far from uncommon in conversational Dutch (Van Kampen 1997: chapt.4). Hence, it is typical input for the child's acquisition procedure. The absence of the Spec.C leads to a high percentage V1 patterns in declaratives. There are two types of such Dutch V1 patterns. The first type is related to an argument gap and is known as topic-drop. ${ }^{9}$ The Spec.C is assumed to hold an empty topic $d$-pronoun (Van Kampen 1997). Examples of topic-drop in the speech of the Dutch mother are given in (33).

Topic-drop (adult Dutch, mother Sarah)

a. $\varnothing$ heeft Marjolein op $t_{D P}$ geschreven.

'(there) has Marjolein on $t_{D P}$ written'

(Marjolein has written on it)

b. $\varnothing \quad$ mag je zelf tDP inschenken.

'(that) may you yourself $t_{D P}$ pour out'

(you may pour it out yourself)

The other type of non-realized Spec.C is not related to an argument gap and is known as narrative inversion. Narrative inversion could be characterized as leaving out the

\footnotetext{
${ }^{9}$ For an analysis of topic-drop, see Van Kampen (1997 : chapt. 4).
} 
unstressed turn-taker or dummy adverb (dus/dan/toen/nu 'so'/'then'/'now'; er 'there'), resulting in a true V1 construction, without argument gap. The examples of narrative inversion in (34) are taken from the mother of Sarah. They show no topic-gap, and turntakers dan/nu/daar ('then/now/there') are not present either.

Narrative inversion (adult Dutch, mother Sarah)

a. doen we de spelletjes even weg

'do we the games a bit away'

(we will put the games away)

b. zijn ze aan het slapen in de trein

'are they on the sleep in the train'

(they are sleeping in the train)

In a (situation-bound) mother-child conversation, narrative inversion is quite frequent in Dutch (14\% in the speech of Sarah's mother, see (31)c), and in Germanic V2 languages in general. ${ }^{10}$

Dutch narrative inversion has been mentioned in the literature as a (clausal) discourse variant for telling a story or a joke. Koeneman (2000: 153), for example, notes that "they typically appear embedded in conversations", with "the effect of making the link to previous discourse more tight". Zwart (1993: 203) argues that V1 narrative inversion involves a null narrative operator in Spec-CP which enforces $\mathrm{V}<+$ fin $>$-to- $\mathrm{C}^{0}$ movement. The acquisition data from CHILDES suggest an origin that is different. The illocution operator from the binary word stage begins to make use of the finite denotationals from week 115 on (cf. (16) in section 2.2). Subsequently, it is the $\mathrm{V}_{<+F,+f i n>}$ illocution marker that sets the stage for acquiring the Spec.F $\Rightarrow$ Spec.C. Narrative inversion (no turn-taker, no topic-gap) is not an additional device. It is rather frequent and an inheritance from the proto-grammar ([operator-topic-comment]). No Spec.C is involved in narrative inversion.

Within less than two months (week 125-132), Sarah's sentences without a Spec.C drop considerably. The position preceding the finite verb has been identified as a position for topics, especially presupposed subject topics, as has been shown in section 3.1. It will not be necessary, though, to postulate and EPP feature to get the Spec.C filled in. The Spec.C need not be filled in from the beginning on. Narrative inversion remains in adult conversation $14 \%$ (cf. (32)). If this option is chosen, there is the presupposition of a close context effect (a narrative, an answer). If that does not fit the situation, one must put in a turn-taker or the presupposed topic (the subject). There are Spec.C functions, but no general Spec.C obligation. The generalization of Spec.C over full stressed A-bar phrases is a later development (Weissenborn 1991, Evers \& Van Kampen 2001: ftn.4). Compare for instance graph B for subject obligation in (36) with graph E (from Van Kampen 1997: 75). Graph E reflects the rise of (obligatory) wh-elements in wh-questions. Before that rise, all wh-questions in the speech of Sarah lack the wh-element in Spec.C, although the $\mathrm{V}<+$ fin $>$ invariably appears in $\mathrm{C}^{\mathrm{O}}$, see (35)a. The later (and adult) wh-question with whelement is given in (35)b.

${ }^{10}$ See for the frequent use of narrative inversion in V2 Swedish conversation Mörnsjö (2002). 
(35)
$\begin{array}{llll}\text { a. } & \text { heb jij } & \text { nou (ge(daan)? } \\ \text { (what)have you then done?' }\end{array}$
(what have you done)

(Sarah week 123)

b. wat heb ik gedaan?
'what have I done?'

(Sarah week 142)

(36) Dutch Sarah: the acquisition of (A-status) subjects and (A-bar) wh-elements

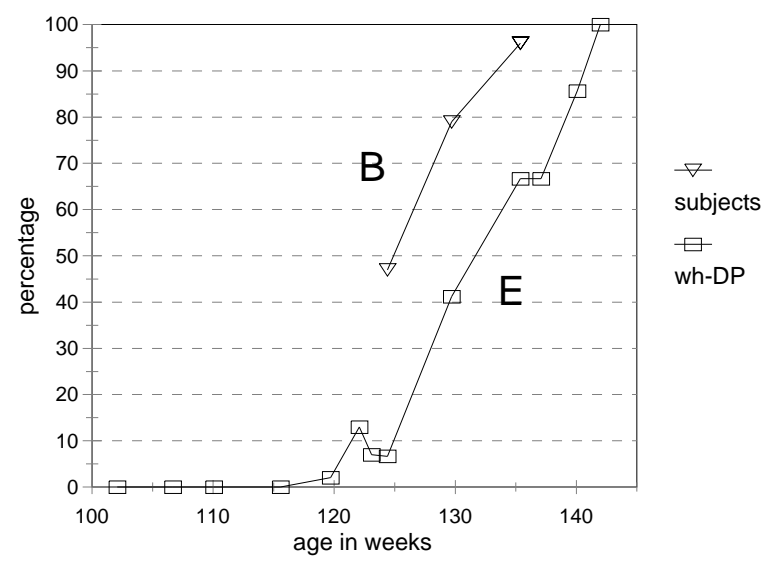

The ambiguity of Spec.C between A-status and A-bar status is repeated in the status of Spec.I in SVO English/French subject wh-questions (who understands that?), but does not occur in the Celtic V1 system.

The Celtic system does not offer its learners a Spec.C phrasal position. There appears no subject DP or subject pronoun in the position before the $\mathrm{V}<+$ fin $>$. The position may be used for turn-takers or for clause-typing operators (e.g. declarative, negation, relative, interrogative). I will follow here Rizzi (1997) and McCloskey (2000) who propose that the clause-introducing particles in Irish occupy the head of a Force/Illocution projection. Since I would like to have that function as well for the $\mathrm{V}<+$ fin $>$ in $\mathrm{C}^{0}$ in Celtic, I must assume a split $\mathrm{C}^{\mathrm{O}}$ with a non-verbal and a verbal head, see (37).

(37)

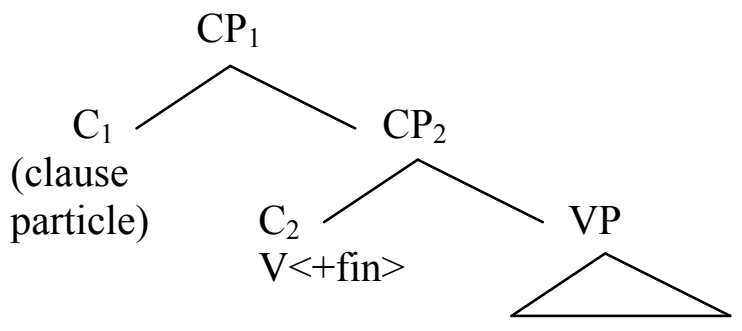

$t_{V}$

In general, the $\mathrm{C}_{1}$ may be optional. If present, $\mathrm{C}_{1}$ is realized by a sentential adverb/operator. If one were to label the $\mathrm{C}_{1}$ clause-initial elements as Spec.C and a parallel to the Germanic Spec.C (as in Bury 2005, Jouitteau 2005), one would need questionable arguments to restrict their use to non-referential and non-phrasal parts of the 
sentence. By contrast, a decision to consider these elements as an additional set of $\mathrm{C}^{\mathrm{o}}$ operators is supported by their non-topic clause-typing function. It may be that some of them are already in that function during the binary clause period in proto-grammar. I expect that the split- $\mathrm{C}^{\mathrm{o}}$ assumption is successfully related to three further acquisitional hurdles that are on the Celtic acquisition program, which by now (that is before the third birthday of most learners) will begin to sharply deviate from Germanic V2

(1) Move $\mathrm{V}<+$ fin $>-$ to $\mathrm{C}_{2}{ }^{\mathrm{O}}$ will not be blocked in subordinates that open with a $\mathrm{C}_{1}$, whereas this blocking by $\mathrm{C}$ is a curious property of West Germanic and almost automatically acquired from the first appearance of subordinates (around the third birthday).

(2) Some of the $\mathrm{C}_{1}<-$ verbal $>$ elements allow a Spec.C for full phrase topicalized material. This property returns for subordinate complementizers that allow the preposing of adverbial phrases in front of the complementizer $\mathrm{C}_{1}$.

(3) The unstressed pronominal cannot appear ever in front of the $\mathrm{V}<+$ fin $>$ due to the lack of a Spec. $\mathrm{C}_{2}$. Hence, unstressed subject pronouns will invariably follow the finite verb. This obviously offers the acquisitional basis for the anti-agreement effect.

The frame in (24) may function to establish the subject configuration in Celtic as well as in Germanic.

Celtic allows a preposed full phrase by means of a special construction When the $\mathrm{C}_{1}$ takes the form of a relative particle fronting a root clause, there is a Spec. $\mathrm{C}_{1}$ in which all kind of relativizable material can be placed. The relative particle announces the corresponding argument gap in the $\mathrm{CP}_{2}$, see the examples in (38) taken from McCloskey (2000).
a. an chéad amhrán eile a bheas againn (the next song we'll have)
$\begin{array}{lll}\text { b. nuair a bõ!os daoine tinn } & \\ \text { 'when aL be [pres-habit-wh] people } & \text { sick' }\end{array}$ (when people are sick)
c. cá h-uair a thiocfas tú 'na bhaile? 'what time aL come [fut-wh] you home' (when will you come home?)
d. chomh luath agus a thiocfas sé 'na bhaile 'as early and aL come [fut-wh] he home' (as soon as he comes home)

If it were possible to drop the relative particle in $\mathrm{C}_{1}$, the system would turn into a V2 system. Compare the Dutch V2 "relative" with agreeing $d$-pronoun in (39)a and its variant without such pronoun in (39)b (cf. Koster 1978).
a. dat liedje $<+$ neuter $>$
'that song
dat $<+$ neuter $>$
ga ik zingen
that $\quad$ go I sing'
(I am going to sing that song) 
b. dat liedje ga ik zingen

'that song go I sing'

(I am going to sing that song)

This suggests that the two types V1 and V2 remain fairly close.

\section{Conclusion}

Celtic V1 and Germanic V2, for example Dutch, have an acquisitional problem in common. They have to identify the finite verb in root clauses as an operator placed in a root-clause initial position. The frequent auxiliaries are the acquisitional bridge. They are identified as clausal modal operators in binary proto-grammar, i.e. the grammar before grammatical features, c.q. functional categories, appear. The non-finite post-posed position of the denotational predicate head is acquired in proto-grammar at the same time. A decisive acquisition step in both systems must be the appearance of the finite variant of the denotational verb in the position of the illocution operator. From that point on, all root clauses are marked by a grammatical $<+$ fin $>$ element that marks them as "illocutionary unit". I proposed that $<+$ fin $>$ is an illocution marker in the position $\mathrm{F}^{\circ}$. The question whether $\mathrm{F}^{0}=\mathrm{C}^{0}$ or $\mathrm{F}^{\mathrm{o}}=\mathrm{I}^{\mathrm{o}}$ is to be decided in a later acquisition step. $\mathrm{V}<+$ fin $>=\mathrm{I}^{0}$ if Spec. $<+$ fin $>$ is the subject. $\mathrm{V}<+$ fin $>=\mathrm{C}^{0}$ if that is not necessarily so. Note that there is a remarkable fact here. No language fills in $\mathrm{I}^{\circ}$ and $\mathrm{C}^{0}$ at the same time. This strange fact follows from the present procedure.

The clauses have a frame $\left[---<+\right.$ fin $\left.>---t_{V<+f i n}>\right]$ and the presence of the subject argument can de noticed by a fixed position in this frame. The variation of certain elements between $<+$ fin $>$ and $<-$ fin $>$ allow the identification of a subset of lexical elements as $\langle+\mathrm{V}\rangle$. The position that the parts of speech are learnable due to the syntactic function of a morphological paradigm is fortunately a fairly traditional point of view.

The identification of $\langle+\mathrm{V}>$ and the main structure of the predicate as $[---\mathrm{F}<+$ fin $>----$ $t_{\mathrm{F}<+f i n}>$ are likely to identify the subject as a referential element positionally related to the $<+$ fin $>$ marking of the predicate. The acquisition steps that can and must establish the subject obligation introduces a typological difference between Celtic and Germanic.

(40)

a. Germanic V2 allows free subject-verb inversion.

b. Celtic V1 excludes a Spec.C and insists on subject-verb inversion for all of its constructions.

c. English SVO resists subject-verb inversion. The subject is invariably Spec. $<+$ fin $>$ in the primary input data.

Within this perspective, V1 and V2 develop into different types of grammar, just after they have established their common point Move $\mathrm{V}<+$ fin $>-$ to- $^{0}$. It is obvious that my arguments lack the quantitative acquisition analysis for Celtic, although the data are present (for Welsh, the Jones corpus in CHILDES, Borsley \& Jones 2001). ${ }^{11}$ Yet, I hope

${ }^{11}$ From the Bangor area : Alaw $(1 ; 6.8-2 ; 3.21)$, Dewi $(1 ; 9.21-2 ; 6.9)$, and Rhys $(1 ; 8.31-2 ; 5.21)$. From the Aberystwyth area : Bethan (1;7.28-2;4.3), Melisa $(1 ; 6.20-2 ; 3.17)$, and Rhian $(1 ; 6.17-2 ; 3.23)$. The corpora cover the acquisition of the finite verb. 
to have demonstrated how such an analysis may substantiate typological problems. The acquisition of the subject obligation has been construed as a feature relation between a $\mathrm{DP}$ and $\mathrm{V}<+$ fin $>$. As in a kind of EPP, $<+$ fin $>$ enhances the projection of $<+\mathrm{V}>$. At the same time, it turned out that the uninterpretable phi-features on $\mathrm{V}<+$ fin $>$ or interpretable Tense cannot have played any role in the acquisition of the subject- $\mathrm{V}<+$ fin $>$ relation. Tense and phi-feature oppositions are acquired after, and plausibly because, the major fact of subject obligation and subject position have been established.

I expect that the longitudinal analysis of child language may solve the typological options and hierarchies in the languages of the world, like a kind of DNA analysis for grammar.

\section{References}

Bayer, J. (2004) 'Decomposing the left periphery: dialectal and cross-linguistic evidence', in: H. Lohnstein \& S. Trissler (eds.) The Syntax and Semantics of the Left Periphery Berlin: Mouton de Gruyter, 59-95.

Besten, H. den (1983) 'On the interaction of root transformations and lexical deletive rules,' in Werner Abraham (ed.) On the Formal Syntax of Westgermania Amsterdam: John Benjamins, 47-131.

Blom, E. (2003) From Root Infinitive to Finite Sentence, $\mathrm{PhD}$ dissertation Utrecht University.

Borsley, R.D. \& B. Morris Jones (2001) 'The development of finiteness in early Welsh', Journal of Celtic Language Learning 6, 9-20.

Briscoe, E.J. (2000) 'Grammatical acquisition: inductive bias and co-evolution of language and the Language Acquisition Device', Language 76(2): 245-296.

Bury, D. (2005) 'Preverbal particles in verb-initial languages', in: A. Carnie, H. Harley \& S. Dooley (eds) Verb-first. Amsterdam: John Benjamins, 135-154.

Bury (this volume)

Chomsky, N. (1975) Reflections on Language New York: Pantheon.

Clahsen, H. (1991) 'Constraints on parameter setting. A grammatical analysis of some acquisition stages in German child language', Language Acquisition 1.4, 361-391.

Dresher, B. E. (1999) 'Charting the learning path: cues to parameter setting', Linguistic Inquiry 30, 27-67.

Emonds, J. E. (1976) A Transformational Approach to English Syntax: Root, Structure-preserving and Local Transformations. New York: Academic Press.

Evers, A. (1981) 'Verb second movement rules', Wiener Linguistische Gazette 26, 15-34.

Evers, A. (1982) 'Twee functionele principes voor de regel "Verschuif het werkwoord", GLOT, 11-30.

Evers, A. \& J. van Kampen (2001) 'E-language, I-language and the order of parameter setting', Uil OTS Working Papers 00105-S-S, Utrecht.

Evers, A. \& J. van Kampen (2008) 'Parameter setting and input reduction', in: T. Biberauer (ed.) The Structure of Parametric Variation, Amsterdam/ Philadelphia: John Benjamins.

Fodor, J.D. (1998) 'Unambiguous triggers', Linguistic Inquiry 29. 1-36.

Haan, G.J. de (1987) 'A theory-bound approach to the acquisition of verb placement in Dutch', in: G.J. de Haan \& W. Zonneveld (eds.) Formal Parameters of Generative Grammar III, 15-30. 
Haegeman, L. (1995) 'Root infinitives, tense and truncated structures in Dutch' Language Acquisition 4(3), 205-255.

Hoekstra, T, \& N. Hyams (1998) 'Aspects of root infinitives', Lingua 106, 81-112.

Hurford, J. (2007) 'The origin of noun phrases: reference, truth and communication', Lingua 117(3), 527-542.

Jakobson, R. (1942) Kindersprache, Aphasie und Allgemeine Lautgesätze. Uppsala: Uppsala Universitets Årsskrift.

Jouitteau, M. (2005) La Syntaxe Comparée du Breton Thèse de doctorat Université de Nantes

Kampen, J. van (1997) First Steps in Wh-movement Delft: Eburon.

Kampen, J. van (2001) 'Bootstraps at two for lexicon and discourse', in: Proceedings of ELA (Early Lexicon Acquisition), Lyon, December 5-8, http://www.let.uu.nl/ Jacqueline.vanKampen/personal/downloadables.htm

Kampen, J. (2004a) 'The learnability of syntactic categories', J. van Kampen \& S. Bauuw (eds.) Proceedings of GALA 2003, 245-256.

Kampen, J. (2004b) 'The rise of predication by EPP', A.Brugos, L Micciulla \& Ch. Smith (eds.) Proceedings of BUCLD 2003, 267-281.

Kampen, J. van (2004c) 'Learnability order in the French pronominal system', in: R. Bok-Bennema, B. Hollebrandse, B. Kampers-Manhe and P. Sleeman (eds.) Selected Papers from Going Romance 2002, 163-183, Amsterdam/Philadelphia: John Benjamins.

Kampen, J. van (2005) 'Language-specific bootstraps for UG categories' International Journal of Bilingualism 9(2), 253-277.

Kampen, J. van (2006a) 'The acquisition of the standard EPP in Dutch and French', in: J. Costa and M.C. Figueiredo Silva (eds.) Studies on Agreement Amsterdam/Philidelphia: John Benjamins.

Kampen, J. van (2006b) 'Early operators and late topic-drop/pro-drop', in: V. Torrens and L. Escobar The Acquisition of Syntax in Romance Languages Amsterdam/Philadelphia: John Benjamins.

Koeneman, O. (2000) The Flexible Nature of Verb Movement, PhD dissertation Utrecht University.

Koeneman (this volume)

Koster, J. (1978) 'Why subject sentences don't exist', in: S.J. Keyser (ed.) Recent Transformational Studies in European Languages Cambridge MA: MIT Press, 53-64.

Krifka, M. (2006) 'Functional similarities between bimanual coordination and topic/comment structure', in: S. Ishihara, M. Schmitz, A. Schwarz (eds.) Interdisciplinary Studies on Information Structure 08 Potsdam.

Lebeaux, D. (1988) Language Acquisition and the Form of Grammar, PhD. dissertation University of Massachusetts.

MacWhinney, B. (2006) The CHILDES Project: Tools for Analyzing Talk, $3^{\text {rd }}$ edition, Lawrence Erlbaum Associates, Mahwah, NJ.

Migdalski (this volume)

Mörnsjö, M. (2002) V1 Declaratives in Spoken Swedish PhD. dissertation Lund University.

Radford, A. (1990) Syntactic Theory and the Acquisition of English Syntax: the Nature of Early Child Grammars of English, Oxford: Basil Blackwell. 
Rizzi's (1997) 'The fine structure of the left periphery', in: L. Haegeman (ed.) Elements of Grammar Dordrecht: Kluwer, 281-337.

\section{Rouveret (this volume)}

Schütze, C.T. \& K. Wexler (1996) 'Subject case licensing and English root infinitives', in: Proceedings of the $20^{\text {th }}$ Boston University Conference on Language Development, 670-681.

Watanabe, A. (1994) 'The role of triggers in the extended split Infl hypothesis: Unlearnable parameter settings', Studia Linguistica 48: 156-178.

Weerman, F. (1989) The V2 Conspiracy Dordrecht: ICG Printing.

Wechsler, S. (1991) 'Verb second and illocutionary force', in: K. Leffel and D. Bouchard (eds.) Views on Phrase Structure Dordrecht: Kluwer, 177-191.

Weissenborn, J. (1991) 'Functional categories and verb movement: The acquisition of German syntax reconsidered', in: Rothweiler (ed.) Linguistische Berichte Sonderheft 3 Spracherwerb und Grammatik, , Göttingen: Westdeutscher Verlag. 190-224

Wexler, K. (1998) 'Very early parameter setting and the unique checking constraint: A new explanation of the optional infinitive stage', Lingua 106: 23-79.

Wijnen, F. (1997) 'Functionele categorieën in Nederlandse kindertaal', Nederlandse Taalkunde 3:178-198.

Zwart, C. J.-W. (1993) Dutch Syntax. A Minimalist Approach PhD dissertation University of Groningen.

Yang, C. (2002) Knowledge and Learning in Natural Language. Oxford: Oxford University Press. 